\title{
O USO DO CONTRATO DE LEITURA NA CARACTERIZAÇÃO DOS DISCURSOS SOBRE CIÊNCIA DAS REVISTAS ESPECIALIZADAS
}

\author{
RAFAELA SAMAGAIA \\ Universidade Federal de Santa Catarina (UFSC) \\ Florianópolis, Santa Catarina, Brasil \\ E-mail: rafaela.samagaia@gmail.com \\ REINALDO BECHLER \\ Universidade Federal de Santa Catarina (UFSC) \\ Florianópolis, Santa Catarina, Brasil \\ E-mail: reibechler@yahoo.com.br \\ DEMÉTRIO DELIZOICOV NETO \\ Universidade Federal de Santa Catarina (UFSC) \\ Florianópolis, Santa Catarina, Brasil \\ E-mail: demetrio@ced.ufsc.br
}




\title{
O USO DO CONTRATO DE LEITURA NA CARACTERIZAÇÃO DOS DIS- CURSOS SOBRE CIÊNCIA DAS REVISTAS ESPECIALIZADAS
}

Resumo: $O$ presente trabalho apresenta três modelos distintos para os discursos sobre a ciência propostos em revistas especializadas, comumente chamadas de divulgação científica. Eles foram obtidos à luz da teoria do Contrato de Leitura de Eliseo Veron e a partir da análise de um corpus de 36 revistas francesas. O artigo discute ainda o papel epistemológico da divulgação científica e a sua contribuição na construção da ciência.

Palavras-chave: Comunicação científica, epistemologia, contrato de leitura.

EL USO DEL CONTRACTO DE LECTURA EN LA CARACTERIZACIÓN DE LOS DISCURSOS ACERCA DE LA CIENCIA DAS REVISTAS

Resumen: El trabajo presenta tres modelos para los discursos acerca de la ciencia, propuesto en revistas especializadas, comúnmente llamadas de Divulgación Científica. Ellos fueran obtenidos a la luz de la teoría del Contracto de Lectura, de Eliseo Verón, y del análisis de un corpus de 36 revistas francesas. El artículo también analiza el papel epistemológico de la comunicación de la ciencia, y su contribución para la construcción de la ciencia.

Palabras clave: comunicación científica, epistemología, Contracto de Lectura

USING THE «READING AGREEMENT» TO UNDERSTAND THE DISCOURSES ABOUT SCIENCE IN SPECIALIZED MAGAZINES

\begin{abstract}
This paper presents three models of discourses about science proposed on specialized magazines frequently called scientific popularization or public understanding of science. They considerer the theory of «Reading Agreement» proposed by Eliseo Veron and where constructed with data from 36 magazines in specialized french press. This paper discusses also the epistemological role of the scientific popularization and it's epistemological contribution to the construction of science.
\end{abstract}

Key words: public understanding of science, epistemology, Reading Agreement 


\section{INTRODUÇÃO}

As relações entre a ciência e a sociedade transformaram-se ao longo da história, do mesmo modo que transformaram-se os regimes de funcionamento da ciência e o papel atribuído ao leigo nesta estrutura (Bensaude-Vincent 2003, Callon 2001). Nos dias de hoje, a interface entre ciência e sociedade apresenta um alto nível de complexidade. Manifestações visíveis deste fato começam a surgir no Brasil e já são uma realidade cotidiana na Europa. Wolton (1997) descreve assim o novo paradigma para as trocas entre leigos e especialistas como sendo a gestão de lógicas diferentes. Em oposição a outros períodos históricos onde uma análise simplista poderia entender a divulgação da ciência como sendo a ligação entre o sábio aplicado e o leigo curioso, hoje uma tal abordagem é impensável. É preciso principalmente gerenciar relações entre a ciência, a política, a comunicação e os públicos. (Wolton, 1997 p. 9) Sequer é simples a tarefa de identificar o que pertence de fato a ciência (ou mantém com ela relações próximas) quando se observa as discussões presentes na esfera pública: Conhecimento produzido por cientistas na indústria segundo uma lógica própria; conhecimento científico utilizado como argumento de venda para produtos de todos os tipos; vacinas e outras campanhas de saúde esvaziadas da sua ciência; controvérsias sócio-científicas que ganham em amplitude com ou sem fundamentação científica e embaladas pelas implicações sociais ou econômicas das decisões e descobertas da ciência. Estes elementos, entre outros, co-habitam nesta fronteira invisível, sutil mas bem real que separa (ou não) a ciência e a sociedade. A comunicação possui assim um papel de grande relevância e materializa, por vezes, a interface, as relações entre os atores, as disputas e as querelas.

Entre as ferramentas da dita divulgação científica estão os suportes escritos que apresentam um interesse particular. Em oposição a efemeridade da linguagem oral presente nos programas de televisão, palestras, cafés científicos, etc. o texto escrito é produzido, compartilhado, lido e relido, corrigido, discutido, modificado. O processo inclui a validação de uma grande quantidade de atores uma vez que é possível ver a versão final antes que ela seja mostrada ao público. Neste sentido, o discurso assim transmitido é, ao mesmo tempo, mais complexo e mais fácil de ser analisado, porque o suporte preserva-o mas reconstrói o contexto de leitura em função do contexto do leitor. (Cheveigné, 1997) As revistas especializadas neste tipo de discurso 
são um objeto ainda mais interessante. Seu alcance é amplo porque podem ser transportadas e arquivadas, são de fácil acesso (bibliotecas públicas e escolares) e seu custo de aquisição é baixo. Elas podem ainda ser lidas e relidas em épocas diferentes uma vez que, ao contrário do jornal cujo interesse é diário, as revistas se apresentam como sendo instrumentos permanentes de informação. Para além destes argumentos práticos, ou melhor seria dizer ao mesmo tempo que eles, a divulgação científica escrita possui uma linguagem própria que influencia fortemente os discursos que ela produz. (Jeanneret, 1994; Moirand, 1997). No caso de revistas especializadas, este fato se reforça pela presença de uma lógica associada ao próprio suporte e as relações entre leigos e especialistas que eles revelam ou propõem.

Uma pesquisa realizada em 2005 com três revistas de divulgação científica francesas buscou investigar as questões acima mencionadas. Utilizou-se para isso um instrumento de análise construído com base no conceito de Contrato de Leitura de Eliseo Veron. Haja vista a data e o contexto geográfico do corpus, os resultados aqui apresentados não se propõem a descrever um retrato da atualidade nem daquele nem deste país. Mas apesar da aparente defasagem, as categorias descritivas e critérios construídos permitem a identificação de três modelos distintos para os discursos sobre a ciência que eles, podem ser facilmente utilizados no contexto atual. Estes modelos teóricos foram assim associados a diferentes Contratos de Leitura estabelecidos entre cada uma das revistas e seus leitores.

Os resultados obtidos com a pesquisa empírica serão em seguida observados a partir da discussão trazida por Bernadette Bensaude-Vincent (2003). Para esta autora, a divulgação científica tem uma função epistemológica maior e contribui diretamente com a construção da ciência. Esta conclusão faz eco à teoria do conhecimento proposta por Ludwik Fleck, segundo a qual a circulação dos saberes entre círculos próximos e distantes da esfera central de produção da ciência tem um impacto considerável naquilo que ela produz. (Fleck, 2010).

\section{A PESQUISA EMPÍRICA}

A pesquisa aqui descrita foi concebida e realizada sob a coordenação da professora Suzanne de Cheveigné (Lamy-Peronnet, 2006) com o objetivo de explicitar os elementos que caracterizam os discursos sobre a ciência propostos nas revistas especializadas, comumente chamadas de revistas de divulgação da ciência. 
O corpus estudado constituiu-se das doze edições publicadas no ano de 2005 por três importantes revistas de divulgação científica francesas: «La Recherche»; "Science et Vie» e "Ça m'intéresse». Estas três revistas claramente diferentes, reúnem uma parcela importante dos leitores francófonos (França, Suíça e outros países de língua francesa). «Science et Vie», destaca-se no quesito tempo de existência, uma vez que seu lançamento data de 1913.

O corpus assim constituído foi analisado segundo parâmetros pré-determinados. 36 exemplares de revistas cuja forma e quantidade de páginas variou consideravelmente. Observou-se assim a capa, o sumário e todos os artigos publicados, sejam eles longos ou curtos.

A capa - Serve para alcançar o leitor, estabelecer contato com ele. Como cada revista busca este contato? Ao que faz referência a capa? A ciência, ao mundo conhecido do leitor ou ao leitor enquanto indivíduo? Observou-se assim a presença de referências exclusivas da ciência (uma molécula, um átomo) ou do leitor (um indivíduo comum, algo que permitisse a ele reconhecer-se na capa da revista). A terceira categoria considerou as ocorrências relativas ao mundo do leitor (lugares ou monumentos por exemplo) ou seu universo pessoal (casa, carro, etc.). As temáticas exploradas também foram observadas separando-se imagens e texto.

A orientação temática dos artigos das revistas - Considerado por Eliseo Veron como exercendo grande influência na concepção do contrato de leitura, a orientação temática ou enquadramento recebeu atenção particular. Ela informa sobre as diferentes visões de mundo propostas pelas revistas e foi avaliada através de categorias construídas para este fim.

Topologia das páginas (presença e importância das imagens) - Este parâmetro constituiu uma parte importante da análise, uma vez que a presença, o tipo e o uso das imagens constitui por si só um poderoso fator de diferenciação das revistas. Encontrou-se tanto páginas brancas com imagens enquadradas quanto grandes fotos e ilustrações preenchendo toda a página e onde a cor predomina. Todas as imagens ocupando mais do que 1/6 (aproximadamente $20 \%$ ) de uma página foram analisadas. Também foi observada a hierarquia atribuída ao conjunto texto + imagem. Qual deles é priorizado? Já o papel da imagem foi categorizado em informativo, ilustrativo, explicativo e emocional e o seu conteúdo (aquilo que elas representam) foi associado à ciência, ao mundo ou ao leitor. Chareaudeau (2005) contribuiu neste ponto com a discussão sobre o que chama de «visées discursives» ou aquilo que visam os discursos. $O$ conceito foi então aplicado às imagens. 
O público visado pelas revistas: Não somente a informação oficial disponível sobre ele, mas também os indicadores presentes no corpo de cada publicação como o "Correio do leitor». A quantidade de questões publicadas e respondidas pela revista, seu nível de dificuldade ou ainda o conteúdo e o tipo das questões foram observados e categorizados. Observou-se ainda a publicidade apresentado nas edições. A que tipo de leitor (idade, categoria socioeconômica, gênero) ele se endereça? Haja vista o preço de uma página publicitária nas revistas em questão e a quantidade de outros suportes publicitários disponíveis para atender as necessidades das empresas, estimou-se que haviam mais informação sobre o público leitor, do que se podia obter diretamente junto as revistas. Gonçalves (2007) em uma pesquisa unicamente voltada à publicidade na revista Scientific American Brasil também discute a importância deste parâmetro na compreensão do contrato de leitura entre um suporte midiático e seu leitor.

No processo de tratamento dos dados obtidos e apesar da precisão e da solidez do instrumento proposto por Veron, atentou-se para o caráter tipicamente volátil associado aos fenômenos individuais ou sociais. Para remediar a esta dificuldade e acessar as características reais do Contrato de Leitura, algumas condições mínimas de validade dos resultados obtidos foram pré-determinadas. A regularidade e a frequência das propriedades observadas estão entre elas. Buscou-se assim identificar uma configuração clara, sistemática e coerente, ainda que para isso tenha sido necessário abandonar dados interessantes.

\section{O CONTRATO DE LEITURA}

Eliseo Veron $(1984,1985)$ introduz a ideia de Contrato de Leitura. Trata-se de um modelo teórico que busca descrever o conjunto das relações estabelecidas entre um leitor ou espectador e uma mídia. Além do conteúdo propriamente dito, cada suporte proporia assim uma visão de mundo a seus leitores. Esta proposta difusa mas claramente identificável se materializa através do dispositivo de enunciação. Quanto mais próximo um suporte se mostra das expectativas de um leitor potencial (ou seja, aqueles que aderem aos conteúdos descritos), mais simpatia ele terá pelo título e maior as chances de que ele se torne um receptor fiel. O caráter inovador da proposta vem da intenção de Veron de articular lingüística, semiótica e sociologia a fim de tratar da forma mais apropriada possível, a leitura enquanto proces- 
so socio-cultural de captura do sentido de um texto, de um discurso ou de uma mídia.

Para Veron $(1984,1985)$, os constituintes desta identidade podem ser identificados através de dois tipos de parâmetros. Os mais evidentes, como a análise dos temas abordados e os mais sutis, que testemunham desta estrutura quase invisível: Como são construídos os títulos e o resumo que os acompanha no começo das matérias? Os artigos contém linguagem técnica? São contempladas as questões de pesquisa, as condições de produção, os limites de validade ou apenas as respostas dadas pela ciência? Os textos descrevem dúvidas ou certezas? Que adjetivos aparecem no corpo dos artigos para referir a ciência? Enquanto algumas categorias de leitores desconfiam de classificativos exagerados como maravilhoso, impressionante, universal, outros sentem-se seguros e confortáveis com a certeza que eles denotam. Mas ainda: Que tipo imagens aparecem? Qual a função delas no texto? Que personagens são convidados a manifestar-se sobre o assunto discutido? Especialistas mostrando confiabilidade no que está sendo dito? Ou cidadãos, facilitando ao leitor a identificação com aqueles para quem o tema é relevante? Através de uma análise detalhada, Eliseo Veron explora o conceito em toda a sua profundidade desvelando muito do que cotidianamente assemelha-se com questões arbitrárias de gosto ou preferência.

O contrato de leitura Veron $(1984,1985)$ seria assim um acordo tácito, não explicitado e no entanto bem conhecido de todos os que dele participam. Para melhor compreende-lo, é preciso antes descrever estes atores:

O emissor: É um personagem real, uma instituição ou pessoa. Aquele que concretamente escreve o texto. Ele tem sentimentos, lembranças, sensibilidades políticas ou religiosas e o conjunto destas características interferem na construção do discurso que ele faz.

O enunciador: É o narrador ou a imagem do emissor contida no discurso. Por exemplo, o ser muitas vezes objetivo, neutro, metódico e desinteressado ao qual o cientista ou o jornalista são com frequência assimilados na mídia.

O destinatário: É a imagem daquele que deverá receber um discurso à ser produzido e que influencia fortemente na sua concepção. No caso da divulgação científica, o nível de detalhamento dos conceitos, a linguagem, os exemplos, são definidos em função dos conhecimentos e interesses daqueles que, supostamente, irão receber o discurso. Não é raro que este destinatário apareça como sendo ingênuo, curioso, desinteressado e um tanto quanto ignorante.

O receptor: É o personagem real, pertencente ao mundo físico, aquele 
que concretamente recebe um discurso. Ele tem sentimentos, lembranças, sensibilidades políticas ou religiosas e o conjunto destas características intervém na construção do seu entendimento sobre o texto lido.

O contrato de leitura pode então ser descrito como sendo uma entidade variável que relaciona estes quatro atores e que se baseia em três parâmetros principais: o enunciado, a enunciação e o enquadramento: i) $O$ enquadramento é um fator essencial e corresponde a visão de mundo difundida pelo texto. Por exemplo, a tendência política do autor que influencia diretamente sua apreciação de um fato, seja ele qual for. ii) O enunciado é o conteúdo, a mensagem propriamente dita, a informação sobre a qual se baseia o texto. Em princípio, este deve ser o ponto fundamental do ato comunicacional uma vez que, apesar das interferências aqui discutidas, o leitor vem ao suporte porque busca informar-se sobre algo. iii) A enunciação é a forma escolhida pelo emissor para dirigir-se ao destinatário.

\subsection{As macro-categorias de Eliseo Veron}

Além dos itens acima mencionados, é possível analisar a simetria de um discurso (ou a falta dela). Nas revistas científicas por exemplo, observa-se que o ato comunicacional é estabelecido entre sujeitos compartilhando uma grande quantidade de conhecimentos. Ele se caracteriza pela presença de uma linguagem explicitamente técnica e um discurso que utiliza definições sem explica-las porque presume-se que sejam conhecidas do interlocutor. No outro extremo, existem discursos assimétricos como os que caracterizam a comunicação entre um professor e um aluno. Identifica-se neste caso a presença de uma grande quantidade de explicações ou mesmo de conselhos baseados no fato de que um sujeito sábio comunica com outro não sábio. Estes papéis e o tipo de discurso estabelecido entre eles também deixam marcas identificáveis no discurso e interferem na forma como o receptor entende o que lhe é dito (Moirand, 1997). A partir destes fatores, Veron (1997) propõem a existência de quatro macro categorias que podem descrever grande parte da situações de comunicação:

O primeiro caso é totalmente interno à ciência e à um campo de estudos: a Comunicação Endógena Intra-disciplinar. Trata-se da situação em que enunciador e destinatário são cientistas trabalhando em uma mesma área. É o exemplo dos congressos ou dos artigos onde cientistas apresentam a outros cientistas, tão conhecedores do campo quanto ele, o resultado de 
suas próprias pesquisas. Esta situação se caracteriza pelo alto nível de simetria e de igualdade de competência entre ambos, o que justifica e legitima o ato comunicacional. Comunicar implica assim em compartilhar. A situação gera também um padrão de comportamento no qual o interlocutor deverá confirmar esta comparabilidade de nível através de perguntas, objeções e comentários apropriados aos padrões do grupo ao qual ambos pertencem.

O segundo caso compreende a comunicação característica das pesquisas interdisciplinares, é a Comunicação Endógena Inter-disciplinar. Nela, pesquisadores de áreas diferentes buscam construir conhecimento sobre um objeto comum. É o físico de partículas em discussão com um bioquímico. Apesar de cada um saber mais ou melhor do que o outro certos aspectos do problema abordado, a troca se dá segundo uma estrutura fundamentalmente diferente daquela em que o cientista discutiria com um leigo. Existe assim um parâmetro relevante, uma espécie de quadro hierárquico que interfere diretamente no ato comunicacional produzido por este tipo de interação. Tanto quanto ou até mais do que o nível de conhecimento propriamente dito. A justificação e a legitimação do ato comunicacional repousam, neste caso, na equivalência hierárquica entre enunciador e destinatário. Ou seja, ambos são produtores de conhecimento, o que contextualiza os saberes e os não-saberes de cada um.

A terceira categoria corresponde a Comunicação Endógena Trans-científica e é o caso mais frequentemente associado à divulgação científica. Ele contempla um especialista que escreve um livro direcionado aos leigos, profere uma conferência ou participa de uma intervenções na mídia. Suas principais características são: i) Um enunciador que se auto-define como cientista, produtor de conhecimento ou representante da ciência. O ponto de partida do ato comunicacional localiza-se assim no interior da esfera científica. ii) O destinatário será definido por diferença. É justamente pelo fato de não ser um cientista que o enunciador vai se dirigir a ele. iii) É a diferença que justifica e legitima o ato comunicacional ao mesmo tempo que estabelece uma hierarquia de posições e de saberes.

O quarto caso é a Comunicação Exógena Sobre a Ciência. Este é o ato comunicacional que se origina e se mantém exterior à esfera científica. Podese falar neste caso, de um discurso que permite um certo desprendimento entre o que se diz e a ciência ela mesma. Algumas revistas ditas de divulgação científica optam por esta possibilidade. Mas a questão neste caso é: Se nem o enunciador nem o destinatário se definem como sendo próximos da 
esfera de produção da ciência, o que origina a diferença entre estes atores e possibilita o ato comunicacional? Se nenhum deles possui conhecimentos institucionalmente reconhecidos, por que um pode explicar algo ao outro? As respostas a estas questões são diversas. O discurso pode por exemplo reunir argumentos de representantes da ciência, recapitular estados da arte do conhecimento ou ainda se posicionar quanto ao um determinado saber ou situação. Deste modo, o enunciador compartilha uma imagem da ciência e daqueles que falam em seu nome. A escolha por este tipo de discurso pode ser voluntária ou mesmo estratégica, uma vez que ele favorece a ideia de que existe uma relativa proximidade entre enunciador e destinatário. Proximidade esta que pode fundamentar algum nível de confiança. Em alguns casos, como nas controvérsias sócio-científicas isto implica em «estar do mesmo lado que o outro»

\section{TRÊS MODELOS DE DISCURSO SOBRE A CIÊNCIA}

Como resultado da análise, obteve-se três modelos distintos para os contratos de leitura representados no Corpus. Uma vez identificados e categorizados, eles foram aproximados às categorias comunicacionais propostas por Veron (1997).

O primeiro modelo, ao qual corresponde a revista «La Recherche» representa a Comunicação endógena interdisciplinar da ciência. Seus artigos privilegiam uma linguagem técnica e demonstram proximidade e cumplicidade com a esfera de produção da ciência. As formas de utilização da palavra do cientista também são emblemáticas desta relação. Além de frequente, ela pode ser utilizada como uma garantia do que é dito pela revista. Vemos assim artigos escritos integralmente por um jornalista, competente para fazê-lo, que terminam com uma fala do especialista. Nenhuma informação relevante é acrescentada, trata-se simplesmente de uma garantia, um acordo de princípio sobre o conteúdo do texto. Os artigos fazem ainda referências sistemáticas à ciência fundamental, não somente explicando-a mas considerando estes conhecimentos como uma referência compartilhada. Desse modo, a revista demonstra que espera do seu leitor, que ele compartilhe parte do saber necessário ao entendimento do conteúdo proposto.

As imagens também possuem uma forma típica. Unificadas, localizadas, enquadradas e subjugadas ao texto. Elas comportam sistematicamente a informação técnica (escala, origem) e sua presença é justificada no corpo dos artigos. 
A comunicação é assim endógena porque tem sua gênese no âmago da ciência. Busca apoio no saber científico para garantir a legitimidade da mensagem por ela propagada. É interdisciplinar por conta da variedade de temas abordados pela revista, reunindo discussões e leitores de diferentes áreas com quem precisa em seguida dialogar. A revista enquanto mediador se configura então como sendo pouco relevante e o ato comunicacional se baseia em referências compartilhadas, mais do que nas explicações dadas. Suzanne de Cheveigné (2000) que analisou a recepção de programas televisivos sobre ciência, encontrou comportamentos equivalentes na sua amostra e atribuiu a esta categoria o nome «mediador apagado». $\mathrm{O}$ ato comunicacional também se justifica mais na proposição de informação precisa e confiável, do que em propostas educacionais, formativas ou na apresentação de informações de utilidade pública.

O segundo modelo, atribuído pela análise à revista «Science et Vie» é o da comunicação endógena trans-científica. Nesta categoria, o enunciador não é mais a ciência ou o cientista, mas um mediador que se apresenta como sendo o portador deste saber. A legitimidade da mensagem é assim conquistada pela valorização da relação permanente com a verdade científica, por isso a comunicação continua a ser endógena. Mas diferente do primeiro modelo, existe uma relação fortemente assimétrica entre a revista e o público que justifica o ato comunicacional. $O$ destinatário aparece aqui como sendo aquele que precisa da informação e o enunciador, aquele que conhece e transmite o que precisa ser conhecido. Nestas condições, o papel da revista enquanto ponte, enquanto mediador entre especialista e leigo, é de buscar junto à ciência o conhecimento e traze-lo íntegro até o destinatário. Nas categorias de Cheveigné (2000) é o «mediador forte».

O corpus estudado demonstram que, quando comparado ao modelo anterior, os artigos deste modelo possuem uma frequência menor da palavra do cientista citada diretamente. Mas as menções e referências à equipes de pesquisa e seus resultados são bastante frequentes. O mediador descreve o assunto ao invés de publicar um relato daquele que o produziu. Quanto aos temas abordados, «Science e Vie» assemelha-se bastante à «La Recherche».

Outro aspecto interessante vem das imagens. A revista usa com frequência um recurso imagético: o plano fechado que confere uma aura científica a qualquer objeto. É o caso de um artigo sobre a fermentação ilustrado pela produção de pães. Nesta reportagem, duas fotos: uma de vários pães idênticos, perfeitamente alinhados, fotografados em plano fechado e ou- 
tra de dois pedaços de pão, cujo plano de tão próximo mal permitia que se reconhecesse o objeto fotografado. Em ambos os casos, a foto evoca uma representação que assemelha-se a estereótipos da ciência, trazendo aquilo que pode ser à primeira vista associado a ela. Este plano fechado, reforçado pelo uso de coloração artificial, também atribui características diversas às imagens. Um embrião preparado para a pesquisa em células tronco pode assim parecer com uma flor ou um animal fantástico.

A revista demonstra, ainda do que no caso anterior, que reconhece seus leitores (apesar das imagens raramente retratarem possíveis usuários). Uma carta aberta é mesmo diretamente dirigida à eles. Nela, a revista não apenas explica, mas justifica as mudanças importantes que seriam feitas no layout da publicação a partir do mês seguinte. Apesar desta atenção individualizada, o que se percebe é a existência de um destinatário tipo, um perfil geral a quem não se atribui qualquer especificidade. Ele é simplesmente um consumidor de discursos sobre a ciência.

Outro ponto importante é a reivindicação da própria revista de uma função pedagógica, um discurso explicativo dos conteúdos científicos que devem permanecer assim acessíveis a todos. Em um editorial, "Science e Vie» afirma que «nada pode ser tão complicado que não possa ser explicado». Interessante é perceber que os resultados da análise não revelam uma intenção didática particular. Um exemplo é o caso das imagens que poucas vezes são utilizadas como sendo portadoras de informação no conjunto texto + imagem. Sequer elas foram categorizadas como sendo facilitadoras da compreensão de um conteúdo. Os dados mostram ainda uma falta frequente de informações sobre escala nas imagens, agravada muitas vezes pela justaposição de objetos em escalas diferente. Apenas conhecendo o conteúdo das imagens é que esta avaliação pode ser feita. Os já mencionados planos fechados agravam este fato. E muito além das imagens, nenhuma outra marca de didaticidade foi encontrada em quantidade maior nos artigos desta revista do que nas demais. Conclui-se deste modo que "Science et Vie», apesar de descrever-se através de intenções de cunho pedagógico, não se dota das ferramentas discursivas apropriadas para este fim. Moirand (1997) discute esta situação de «mise en scène» ou encenação de um padrão de didaticidade, que quando analisado com cuidado, não se repercute em um interesse real por tornar mais sábio o interlocutor. Os dados obtidos através da análise mostram mesmo o contrário: a revista favorece, muito mais do que as suas concorrentes, a teatralização, a ideia de uma ciência espetacular 
e inquestionável que convida simplesmente à admiração.

A terceiro modelo corresponde ao que Veron (1997) chama de comunicação exógena da ciência, onde nem o enunciador nem o destinatário procuram associar-se diretamente as esferas de produção científica. Neste caso, o ato comunicacional se justifica de forma equivalente ao caso anterior, ou seja, através de um destinatário que busca informação e um enunciador que traz a informação procurada. A diferença fundamental é que nesta terceira situação, a qual corresponde a revista «Ça m'intéresse», o próprio enunciador reivindica um lugar exterior à ciência. Deste modo, ele pode mais facilmente defender os interesses do público com quem dialoga sistematicamente. «Mediador forte» (Cheveigné, 2000) a revista olha para a ciência de longe e descreve ao leitor, o que vê. Se mostra digno de confiança não porque é próxima da fonte de conhecimento, mas porque é próximo daquele que lê. Este enunciador não tem assim compromisso algum com a descrição de conteúdos científicos e sim com a abordagem de assuntos representativos dos interesses dos leitores. Quando necessário, a ciência e seus conteúdos são convocados. $O$ ato de comunicação é assim sustentado por essa relação de confiança e a revista busca pela cumplicidade com o leitor, o que se materializa através da linguagem coloquial (reconhecida como sendo a do seu leitor) e a presença do humor. Nas imagens, sistematicamente ilustrativas, o leitor está majoritariamente presente. Mesmo objetos científicos como medicamentos ou equipamentos ganham pernas, braços e principalmente um rosto tornando-se assim humanizados.

Constatou-se que o contrato de leitura proposto no modelo 3 influencia também as temáticas discutidas, o recorte proposto e a forma de tratamento dos assuntos. Temas científicos aparecem assim muitas vezes descritos como parte de contextos que enfocam prioritariamente as problemáticas da vida cotidiana.

Em um balanço do que foi obtido para cada revista, parece apropriado afirmar que o modelo 1, ao qual pertence a revista «La Recherche» se caracteriza pela precisão e sobriedade. "Science et Vie», identificada como sendo o modelo 2, contribui com uma devoção sem falhas à ciência e a valorização da beleza nela contida que seduz indubitavelmente. Quanto ao terceiro modelo, da revista «Ça m'intéresse» ele se demarca pela mistura, pela composição. De um certo ponto de vista e apesar das críticas que são com frequência feitas a este tipo de abordagem dos temas científicos, não se pode deixar de atribuir-lhe o mérito de alcançar públicos que não aceitariam os demais 
contratos de leitura. É preciso ainda reconhecer sua capacidade de perceber e divulgar a ciência existente na interface entre inúmeros outros saberes. Tantos que, em alguns momentos, torna-se difícil decanta-la, ainda que os dados indiquem sua presença. Se para muitos a ciência vista deste modo é impura, para outros, não há outra forma de socializa-la verdadeiramente. O que a análise parece revelar é que as diferenças nestes três modelos, os torna complementares e não exclusivos.

\section{CONSIDERAÇÕES SOBRE O PAPEL DA DIVULGAÇÃO CIENTIFICA}

Para melhor contextualizar e explorar os resultados desta pesquisa empírica, é preciso introduzir uma idéia: mais do que simplesmente difundir resultados produzidos por uma ciência cuja gênese se dá em total ruptura com os leigos, a divulgação científica possui um papel constitutivo da própria ciência.( Bensaude-Vincent, 2003) Para esta autora, o conjunto de estratégias comunicacionais utilizadas pela divulgação científica, tem como principal objetivo, contribuir com a objetivação da ciência. Para isso, seria necessário retira-la do seu contexto de construção que a torna, de certa forma, localizada. Isso porque ele a associa a certas condições, sem as quais os resultados não são mais os mesmos. Assim, com a justificativa de melhor explica-la, a divulgação científica recorta conclusões e resultados e os transporta para o mundo real, associando-os a um novo contexto: uma promessa de utilidade por exemplo que se materializa nas páginas de uma revista.

Para Bensaude-Vincent, quanto mais complexo, árduo, formal e inacessível é um saber, mais facilmente ele será reconstruído como uma manifestação de uma natureza simples e grandiosa. Quanto mais tempo um cientista consagra à construção de protocolos e equipamentos de medida, quanto maior a quantidade de gestos repetitivos realizados pelos membros de uma equipe para chegar a um resultado, mais ele será o fruto da genialidade daquele que o descobriu. Assim, esta realidade independente de qualquer observador, estas múltiplas perspectivas que se substituem as condições de produção que são únicas, longe de contextualizar o saber científico ou de torna-lo mais acessível, constroem uma idéia de universalidade, de objetividade muito mais difícil de ser questionada do que aquelas que se teria se apenas existisse a lógica científica.

Bensaude-Vincent reforça este argumento através de episódios da história da ciência. Pasteur por exemplo, reconheceu o papel da opinião públi- 
ca esclarecida para o avanço da ciência. Para o eminente cientista, apresentar seus resultados ao público leigo é uma forma suplementar de testa-los (Bensaude-Vincent, 2003 p. 161) Do mesmo modo, Jean Perrin escolheu a divulgação científica para apresentar os resultados obtidos nas medidas realizadas utilizando-se treze métodos diferentes e independentes para contar indiretamente os constituintes elementares de uma amostra: é o nascimento da constante de Avogadro N. Porque fazer uma descrição de tamanha relevância em um artigo de divulgação da ciência? Outro exemplo é médico Rudolf Virchow que já no século XIX utiliza uma revista de divulgação da ciência como parte das ferramentas que fazem avançar seu trabalho (Bechler 2012). Ele faz aliás a crítica agora clássica mas precursora a seu tempo, de que as formas de comunicação entre leigos e cientistas não são apropriadas à velocidade de desenvolvimento da ciência e que elas precisavam ser revistas pelo bem das duas esferas: a pública e a científica. Mais recentemente, durante uma entrevista em 2001, o físico de altas energias Michel Crozon respondeu a um jornalista interessado em saber porque um eminente cientista ocupava-se de divulgação científica: «Divulgo, para melhor compreender o que faço». Em cada um destes casos, estamos bem distantes da idéia de tradução, de simplificação ou na infantilização do público ignorante que precisa ser acompanhado em sua relação com a ciência.

O benefício oferecido por este tipo de discurso sobre a ciência mostra-se fundamental e particularmente importante quando as ciência se especializam, afastando-se cada vez mais das questões e situações do mundo real. Apesar desta aparente distância, ainda é necessário que a esfera pública compreenda a relevância do trabalho do cientista e de fato, dados mostram a concomitância entre o processo de especialização da ciência e o crescimento da divulgação científica. (Bensaude-Vincent, 2002 p. 164)

A idéia de que a divulgação da ciência contribui diretamente com a própria ciência, faz eco também à teoria do conhecimento proposta por Ludwik Fleck. Ao descrever o processo de produção do conhecimento científico, o autor assume que a circulação dos saberes entre círculos próximos e distantes da esfera central de produção da ciência tem um impacto considerável naquilo que aceita-se posteriormente como sendo a ciência produzida.

As discussões trazidas neste artigo evocam algumas conclusões importantes. Uma delas refere-se as revistas especializadas em discursos sobre a ciência endereçados ao público leigo. Apesar do aparente distanciamento que existe entre elas, das diferenças observadas em seus Contratos de Lei- 
tura, uma semelhança vai reuni-las definitivamente: todas tem o seu foco nas questões relativas aos conteúdos da ciência. Elas pertencem assim ao que Callon (2000) chamou de modelo da instrução pública. As discussões trazidas por Bensaude-Vincent (2003) e Ludwik Fleck (2010) nos lembram em seguida, que há muito mais do que isso em jogo. Se de fato a divulgação científica exerce uma função importante na gênese da ciência, o que aconteceria se surgirem de toda parte propostas mais democráticas, mais dialógicas para as trocas entre a ciência e a sociedade? Propostas que, para além do conteúdo, possibilitassem a construção de um diálogo verdadeiro? Muitas pistas vem sendo lançadas e exploradas neste sentido (Callon, 2000, Bensaude-Vincent, 2003), novas práticas vem ganhando terreno, recolocando os elementos desta complexa equação. Como estas iniciativas poderiam ou vão impactar na ciência do futuro? Só a história nos dirá.

\section{REFERÊNCIAS}

BECHLER, Reinaldo Guilherme. Hansen versus Neisser: controvérsias científicas na 'descoberta' do bacilo da lepra. História, Ciências, Saúde - Manguinhos, Rio de Janeiro, v.19, n.3, p. 815 - 841, jul.-set. 2012.

BENSAUDE-VINCENT, Bernadette. La science contre l'opinion: histoire d'un divorce Paris, Seuil, 2003. $291 \mathrm{f}$.

CALLON, Michel. Des differentes formes de démocratie technique Les cahiers de la sécurité intérieure, 39, INHES pp. 37-55. 2000

CHARAUDEAU, Patrick Les médias et l'information L'impossible transparence du discours Bruxelles: Editions de Boeck, 2005. 250 páginas.

CHEVEIGNÉ, Suzanne de. La science dans une société médiatisée Hermès Paris, n. 21 CNRS Éditions, p. 15 - 22, 1997.

CHEVEIGNE Suzanne L'environnement dans les journaux télévisés Médiateurs et visions du monde CNRS Editions, Paris, 2000.

DELIZOICOV, Demétrio. Sociogênese do conhecimento e pesquisa em ensino: contribuições a partir do referencial flekiano. Cad. Bras. Ens. Fís., Florianoópolis, v.19, n. especial, p. 52-69, 2002

DELIZOICOV, Demétrio. Fleck e a epistemologia pós-empirismo lógico. In FAVERO, Maria Helena; CUNHA, Célio (Coord.). Psicologia do Conhecimento - O diálogo entre as ciências e a cidadania. Brasília; UNESCO, Instituto de Psicologia da UNB e Liber Livro 2009. p. 233-258.

FLECK, Ludwik. Gênese e desenvolvimento de um fato científico Belo Horizonte: Fabrefactum, 2010. 205 páginas.

GONÇALVES Elizabeth Moraes. Publicidade e Ciência: a «gramática de produção» do 
anúncio publicitário em Scientific American Brasil Revista Comunicação Midiática, Bauru, 2007.

JEANNERET, Yves. Écrire la science: formes et enjeux de la vulgarisation Paris, Presse Universitaire de France (PUF), 1994. $398 \mathrm{f}$.

JURDANT, Baudoin. Falar a ciência? In Vogt, Carlos (Coord.). Cultura científica Desafios. São Paulo; Editora da Universidade de São Paulo: FAPESP 2006. p. 44-55.

FLECK, Ludwik. Gênese e desenvolvimento de um fato científico Belo Horizonte: Fabrefactum, 2010. 205 páginas.

LAMY-PERONNET, Rafaela Samagaia. Caractéristiques des discours à propos de la science dans les magazines non scientifiques. 2006. 70 f. Dissertação (Mestrado em Informação, Comunicação e Mídias) - Faculdade de Ciências Econômicas e Sociais, Universidade de Genebra, Genebra, 2006.

MOIRAND Sophie. Formes discursives de la diffusion des savoirs dans les médias Hermès Paris, n. 21 CNRS Éditions, , p. 33 - 44, 1997.

VERON, Eliseo. Quand Lire c'est faire: l'énonciation dans les discours de la presse écrite Sémiotique II, Paris, IREP 1984.

VERON, Eliseo. L'analyse du contrat de lecture: Une nouvelle méthode pour les études de positionnements de supports presse» in Les médias. Expériences, recherches actuelles, applications, Paris, IREP. 1985

VERON, Eliseo. De la vulgarisation à la communication Hermès Paris, n. 21 CNRS Éditions, , p. 9 - 14, 1997.

WOLTON, Dominique. Entre l'épistémologie et la communication Hermés Paris, n. 21 CNRS Éditions, , p. 25 - 32, 1997 


\section{Rafaela Samagaia}

Doutoranda do programa de Pós Graduação em Educação Científica e Tecnológica (PPGECT / UFSC). Rafaela é ainda licenciada e bacharel em Física pela UFSC, mestre em Educação científica (PPGECT / UFSC) e mestre em Comunicação científica pela Universidade de Genebra (UNIGE - Suíça).

\section{Reinaldo Bechler}

Pós doutorando do programa de Pós Graduação em Educação Científica e Tecnológica (PPGECT / UFSC). Reinaldo é ainda licenciado em História (UFMG), doutor em História Contemporânea pela Julius-Maximillians-Universität Würzburg e pós-doutor em História da Ciência (UFMG)

\section{Demétrio Delizoicov Neto}

Professor do Departamento de Metodologia de Ensino da UFSC. Demétrio é licenciado em Física pela Universidade de São Paulo e doutor em Educação pela Universidade de São Paulo.demetrio@ced.ufsc.br 